\title{
Littermate Influence on Infant Growth in Mice: Comparison of SJL/J and ICR as Cotransferred Carrier Embryos
}

\author{
Ryosuke KANEKO, Toshie KAKINUMA, Sachiko SATO, Atsushi JINNO-OUE, and
} Hidekazu HATA

Bioresource Center, Gunma University Graduate School of Medicine, 3-39-22 Showa-machi, Maebashi, Gunma 371-8511, Japan

\begin{abstract}
In mice, a minimum number of healthy embryos is required to trigger and maintain pregnancy. Therefore, when recovering mouse embryos from a limited litter, one useful technique is to transfer carrier ICR embryos along with the embryos of interest, a technique referred to as cotransfer. In this study, we examined suitable mouse strains for cotransfer with C57BL/6J (B6) embryos in regards to the maintenance of pregnancy, number of pups born, intrauterine growth, and postnatal growth. Because the coat color of B6 is black, we compared two white coat-colored strains, SJL/J and ICR. Cotransfer of SJL/J and ICR embryos had similar effects on maintenance of pregnancy, number of pups born, and intrauterine growth. However, the postnatal growth of B6 mouse pups cotransferred and grown with SJL/J pups was better than for B6 mouse pups cotransferred and grown with ICR pups, suggesting competition among littermates. These results demonstrate that cotransfer of SJL/J embryos will be useful not only as carrier embryos with B6-background embryos but also as a model system to examine littermate competition.
\end{abstract}

Key words: C57BL/6, cotransfer, embryo transfer, ICR, SJL/J

Introduction

An enormous number of genetically engineered mouse strains have been developed to date. To preserve these strains, cryopreservation of embryos and/or sperm has been widely used [6, 7]. Furthermore, the transportation of cryopreserved embryos/sperm between research facilities has become an important method for the exchange of mouse strains that minimizes the risk of spread of infectious diseases as well as animal escape or death in transit [9].

After receiving samples, embryo transfer is performed to reproduce the mouse strains derived from cryopreserved embryos or produced embryos by in vitro fertil- ization using cryopreserved sperm. A minimum number of healthy embryos is required to be transferred to a recipient to achieve establishment and maintenance of pregnancy in mice [15]. Therefore, when recovering mice from cryopreserved embryos or sperm, special precautions must be taken during handling of the cryopreserved material in order to obtain a sufficient number of healthy embryos [24]. However, even when these precautions are taken by skilled researchers, a limited number of healthy embryos are still obtained in some cases.

To overcome this issue, one useful option is to transfer carrier ICR embryos along with the embryos of interest, a procedure referred to as cotransfer. Although the

(Received 2 February 2014 / Accepted 3 April 2014 / Published online in J-STAGE 9 July 2014)

Address corresponding: R. Kaneko, Bioresource Center, Gunma University Graduate School of Medicine, 3-39-22 Showa-machi, Maebashi,

Gunma 371-8511, Japan

C2014 Japanese Association for Laboratory Animal Science 
usefulness of ICR embryo cotransfer is well known $[4,12,16]$, investigations of suitable mouse strains to use in cotransfer have been limited.

In this study, we explored potential mouse strains for their suitability for embryo cotransfer in regard to maintenance of pregnancy, number of pups born, intrauterine growth, and postnatal growth. Because one of the most common background strains for genetically engineered mice is $\mathrm{C} 57 \mathrm{BL} / 6 \mathrm{~J}$ (B6), which has a black coat color, we used B6 as the strain of interest and embryos from $\mathrm{SJL} / \mathrm{J}$ and ICR strains, which have white coat colors, as the cotransferred embryos. The reason for comparing the $\mathrm{SJL} / \mathrm{J}$ and ICR strains is the large difference in body weight between them, as we expected that the body size of littermates may influence growth of mouse pups/embryos. It is expected that identification of suitable mouse strains for use in cotransfer with B6 embryos will contribute to the efficient production of genetically engineered mice.

\section{Materials and Methods}

\section{Experimental design}

The embryos used in this study were generated by in vitro fertilization (IVF) and were subsequently transferred to recipient mothers after cryopreservation and thawing as described by Nakagata et al. [17, 23]. Throughout this study, 6 to 7 B6 embryos and 6 to 7 $\mathrm{SJL} / \mathrm{J}$ or ICR embryos were transferred per oviduct, with a total of 27 to 28 embryos transferred per recipient mother. Increasing the number of transferred embryos can improve the embryo transfer efficiency of mouse strains with poor reproductive performance [11]. Furthermore, we intended to perform the examinations under a nutrition-limited condition. Therefore, the number of embryos transferred per recipient mother was larger than in the methods described by Takeo and Nakagata [23]. In experiment 1 , the effect of embryo cotransfer (SJL/J or ICR) on the rate of pregnancy and number of pups born was examined. In experiment 2 , the effect of embryo cotransfer (SJL/J or ICR) on postnatal growth of B6 mouse pups was examined by measuring the body weight of each pup. In this experiment, all mice were allowed to give birth naturally, and the number of pups was adjusted to 3 for each strain at postnatal day 1 . The three heaviest mice for each strain were left. The body weights were determined on postnatal days 1,7 , and 21 . In experiment 3 , the effect of embryo cotransfer $(\mathrm{SJL} / \mathrm{J}$ or ICR) on intrauterine growth of $\mathrm{B} 6$ mouse pups was examined. Recipient mice were sacrificed at 18.5 days post coitum (dpc), and the body weights of all embryos were determined.

\section{Animals}

The C57BL/6J (B6) and ICR mice were purchased from Japan SLC while the SJL/J mice [JAX Mice Strain SJL/J (Stock Number 000686)] were from Charles River Laboratories Japan. These mice were used as donors for sperm (from mice 12-15 weeks of age) and oocytes (from B6 mice 4 weeks of age and ICR and SJL mice 8 weeks of age). ICR mice (8-16 weeks of age; Japan SLC) were used as recipients of 2-cell embryos. All animals were maintained in a specific pathogen-free space under a 12-h light/dark regimen. Experimental procedures were performed in accordance with the Guide for the Care and Use of Laboratory Animals of the Science Council of Japan and were approved by the Animal Experiment Committee of Gunma University.

\section{Embryo manipulation}

The procedures for IVF, cryopreservation of sperm and 2-cell embryos, and embryo transfer were performed according to the methods described previously $[17,23]$. All the embryos were transferred at the 2-cell stage into the oviducts of $0.5 \mathrm{dpc}$ recipient mice. Superovulation was induced using equine chorionic gonadotropin and human chorionic gonadotropin (ASKA Pharmaceutical Co., Ltd., Tokyo, Japan). The media were obtained from Ark Resource (Kumamoto, Japan) and Kyudo Co., Ltd. (Saga, Japan).

\section{Statistical analysis}

Statistical analysis was performed using GraphPad Prism Version 6.0 (GraphPad Software, La Jolla, CA, USA). Data were analyzed by ANOVA, with a value of $P<0.05$ considered to be significant.

\section{Results}

Experiment 1: Effect of cotransferred strain on pregnancy rate and number of pups/embryos

At first, we prepared frozen B6, SJL/J, and ICR 2-cell embryos and verified their performances in regard to freeze-thawing and in vivo development (Table 1). After carrying out IVF, cryopreservation, and thawing, 2-cell B6 embryos were divided into two groups. The 2-cell 
Table 1. Comparison of in vitro fertilization rates, survival rates after freeze-thawing, and in vivo development in B6, SJL/J, and ICR mice

\begin{tabular}{|c|c|c|c|c|c|c|c|c|c|c|}
\hline \multirow{2}{*}{$\begin{array}{l}\text { Strains } \\
\\
\text { Female } \\
\times \text { male }\end{array}$} & \multicolumn{4}{|c|}{ In vitro fertilization } & \multicolumn{3}{|c|}{ Freeze-thawing } & \multicolumn{3}{|c|}{ In vivo development } \\
\hline & $\begin{array}{c}\text { No. } \\
\text { of } \\
\exp \end{array}$ & $\begin{array}{l}\text { No. of } \\
\text { females }\end{array}$ & $\begin{array}{l}\text { No. of in- } \\
\text { seminated } \\
\text { oocytes }\end{array}$ & $\begin{array}{l}\text { No. of 2-cell } \\
\text { embryos }(\%)^{\mathrm{a})}\end{array}$ & $\begin{array}{l}\text { No. } \\
\text { of } \\
\exp \end{array}$ & $\begin{array}{l}\text { No. of } \\
\text { thawed } \\
\text { 2-cell } \\
\text { embryos }\end{array}$ & $\begin{array}{l}\text { No. of surviving } \\
\text { 2-cell embryos } \\
(\%)^{\mathrm{a})}\end{array}$ & $\begin{array}{l}\text { No. of } \\
\text { trans- } \\
\text { ferred } \\
\text { 2-cell } \\
\text { embryos }^{\text {b) }}\end{array}$ & $\begin{array}{l}\text { No. } \\
\text { of re- } \\
\text { cipients }\end{array}$ & $\begin{array}{l}\text { No. of live pups } \\
(\%)^{\text {a })}\end{array}$ \\
\hline $\begin{array}{l}\mathrm{B} 6 \\
\times \mathrm{B} 6\end{array}$ & 7 & 91 & 3,086 & $2,120(69.7 \pm 12.2)^{\mathrm{c}}$ & 16 & 544 & $451(83.4 \pm 14.9)^{\mathrm{c}}$ & 116 & 5 & $47(40.7 \pm 5.7)^{\mathrm{c}}$ \\
\hline $\begin{array}{l}\mathrm{SJL} / \mathrm{J} \\
\times \mathrm{SJL} / \mathrm{J}\end{array}$ & 7 & 83 & 1,981 & $1,405(74.5 \pm 16.0)^{\mathrm{c}}$ & 11 & 394 & $261(66.6 \pm 17.7)^{\mathrm{d}}$ & 48 & 2 & $16(33.3 \pm 29.5)^{\mathrm{c}}$ \\
\hline $\begin{array}{l}\mathrm{ICR} \\
\times \mathrm{ICR}\end{array}$ & 4 & 57 & 1,296 & $795(62.8 \pm 9.3)^{\mathrm{c}}$ & 9 & 239 & $172(73.6 \pm 13.9)^{\mathrm{cd}}$ & 65 & 3 & $45(69.3 \pm 10.1)^{\mathrm{d}}$ \\
\hline
\end{tabular}

a) Results are expressed as means \pm SD. b)Twenty-to-twenty eight 2-cell embryos per pseudopregnant ICR recipient were transferred. c-d) Values in the same column without a common superscript are significantly different $(P<0.05)$.

Table 2. Developmental ability of the cotransferred embryos of B6 with SJL/J or ICR

\begin{tabular}{|c|c|c|c|c|c|c|c|}
\hline Type of cotransfer & $\begin{array}{l}\text { Strain of } \\
\text { embryo }\end{array}$ & $\begin{array}{l}\text { No. of trans- } \\
\text { ferred 2-cell } \\
\text { embryo }\end{array}$ & $\begin{array}{l}\text { No. of } \\
\text { recipi- } \\
\text { ents }\end{array}$ & $\begin{array}{l}\text { No. of } \\
\text { pregnancy } \\
(\%)\end{array}$ & $\begin{array}{c}\text { No. of live } \\
\text { pups/embryos } \\
(\%)^{\text {a) }}\end{array}$ & $\begin{array}{c}\text { No. of dead } \\
\text { pups/embryos } \\
(\%)^{\text {b) }}\end{array}$ & $\begin{array}{l}\% \text { of live pups/embry- } \\
\text { os per recipient }{ }^{\mathrm{c}, \mathrm{d})}\end{array}$ \\
\hline \multicolumn{8}{|l|}{ Examined at $P 1$} \\
\hline \multirow[t]{2}{*}{ B6 \& SJL/J } & B6 & 98 & \multirow{2}{*}{7} & \multirow{2}{*}{$7(100)$} & $41(41.8)$ & $0(0)$ & $41.0 \pm 13.3$ \\
\hline & $\mathrm{SJL} / \mathrm{J}$ & 97 & & & $49(50.5)$ & $0(0)$ & $50.6 \pm 14.1$ \\
\hline \multirow[t]{2}{*}{ B6 \& ICR } & B6 & 81 & \multirow{2}{*}{6} & \multirow{2}{*}{$6(100)$} & $32(39.5)$ & $1(1.2)$ & $39.6 \pm 14.9$ \\
\hline & ICR & 84 & & & $49(58.3)$ & $0(0)$ & $58.3 \pm 15.9$ \\
\hline \multicolumn{8}{|c|}{ Examined at $18.5 \mathrm{dpc}$} \\
\hline \multirow[t]{2}{*}{ B6 \& SJL/J } & B6 & 56 & \multirow{2}{*}{4} & \multirow{2}{*}{$4(100)$} & $21(37.5)$ & 2 & $37.5 \pm 9.0$ \\
\hline & $\mathrm{SJL} / \mathrm{J}$ & 56 & & & $31(55.4)$ & 1 & $55.4 \pm 21.3$ \\
\hline \multirow[t]{2}{*}{ B6 \& ICR } & B6 & 42 & \multirow[b]{2}{*}{3} & \multirow{2}{*}{$3(100)$} & $20(47.6)$ & 1 & $47.6 \pm 10.9$ \\
\hline & ICR & 42 & & & $30(71.4)$ & 1 & $71.4 \pm 28.6$ \\
\hline
\end{tabular}

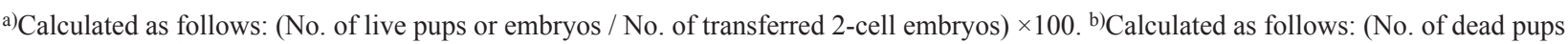
or embryos / No. of transferred 2-cell embryos $) \times 100$. ${ }^{c}$ Results are expressed as means \pm SD. ${ }^{\mathrm{d}}$ Note that values did not significantly differ between groups $(P<0.05)$.

B6 embryos were then cotransferred into the oviducts of ICR females with 2-cell SJL/J embryos (B6 \& SJL/J) in one group and with 2-cell ICR embryos (B6 \& ICR) in the other group (6-7 B6 embryos and 6-7 SJL/J or ICR embryos per oviduct; total of 27-28 embryos per female). Next, we examined the effect of the cotransferred strain on pregnancy rate and number of pups/embryos (Table 2). In both groups all recipients became pregnant, and similar numbers of live pups/embryos were obtained $(P>0.05)$. Thus, compared with ICR embryos, cotransfer of SJL/J 2-cell embryos did not adversely affect the pregnancy rate or the number of pups/embryos.

\section{Experiment 2: Effect of cotransferred strain on postnatal growth of B6 pups}

We next measured and compared the postnatal growth of B6 mouse pups. After natural birth, the numbers of live and dead pups were recorded, and the body weights of the live pups were measured at postnatal day 1 (P1) (Figs. 1A left and 1B left). The ICR pups were the largest among the 4 groups. Importantly, B6 pups cotransferred with SJL/J embryos were significantly larger than B6 pups cotransferred with ICR embryos $[1.52 \pm 0.21$ $(\mathrm{n}=41)$ vs. $1.36 \pm 0.18(\mathrm{n}=32)$, mean $\pm \mathrm{SD}]$. In the $7 \mathrm{~B} 6$ \& SJL/J cotransferred recipients, all B6 pups lived, while in the 6 B6 \& ICR cotransferred recipients, one B6 pup was found dead (Table 2). After body weight measurement, the number of pups was adjusted to 3 for each strain at postnatal day 1, resulting in a total of 6 pups per mother. At P7 (Figs. 1A middle and 1B middle) and P21 (Figs. 1A right and 1B right), all pups were healthy. The number of pups weaned was equal to number of pups left at P1. Importantly, at P7 and P21, the B6 pups cotransferred with $\mathrm{SJL} / \mathrm{J}$ embryos were significantly 

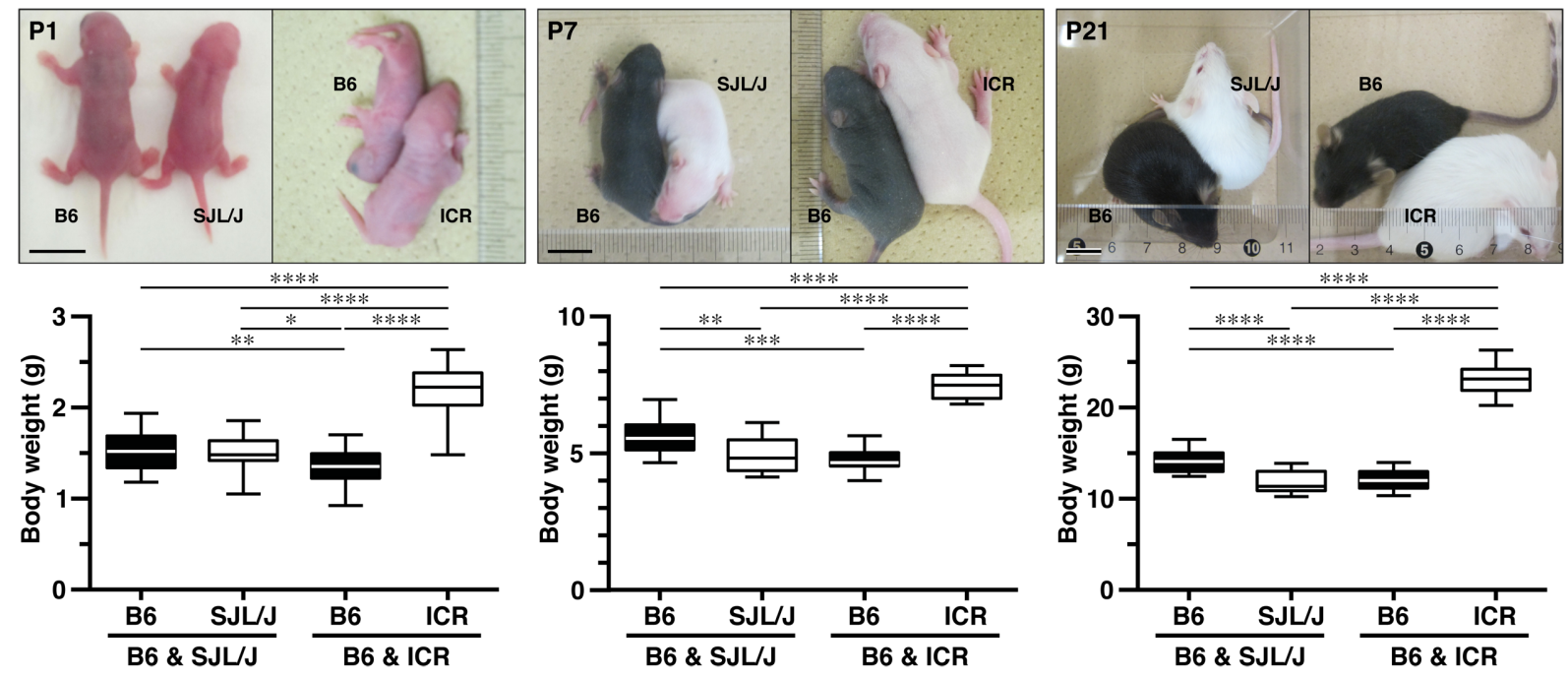

Fig. 1. Cotransferred embryos influence postnatal growth of B6 mice.

(A) Representative images showing B6 \& SJL/J and B6 \& ICR mice at P1 (left), P7 (middle) and P21 (right). (B) Box plots comparing the body weights of B6 pups and cotransferred pups (SJL/J or ICR). There were 41, 21, and 21 B6 pups from B6 \& SJL/J cotransfer at P1, P7, and P21, respectively. There were 49, 21, and $21 \mathrm{SJL} / \mathrm{J}$ pups from B6 \& SJL/J cotransfer at P1, P7, and P21, respectively. There were 32, 18, and 18 B6 pups from B6 \& ICR cotransfer at P1, P7, and P21, respectively. There were 49,18 , and 18 ICR pups from B6 \& ICR cotransfer at $\mathrm{P} 1, \mathrm{P} 7$, and $\mathrm{P} 21$, respectively. $* P<0.05 ; * * P<0.01$; $* * * P<0.001 ; * * * * P<0.0001$. The scale bars in A represent $1 \mathrm{~cm}$.

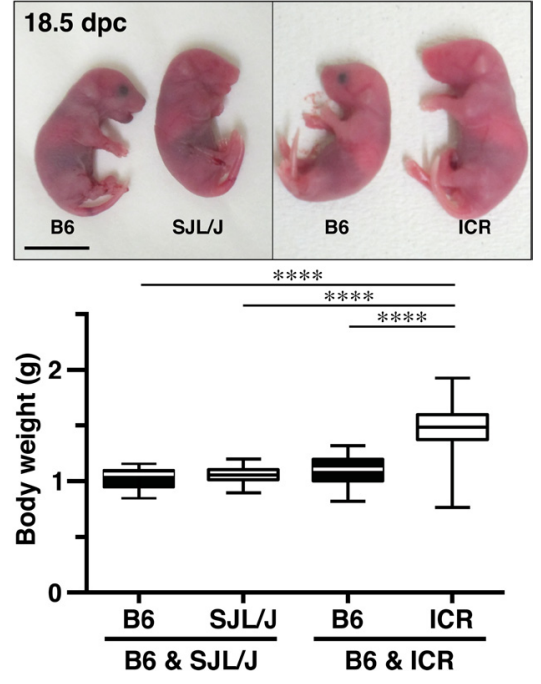

Fig. 2. No apparent effect of cotransferred embryos on intrauterine growth of B6 embryo.

(A) Representative images showing B6 \& SJL/J and B6 \& ICR embryos at $18.5 \mathrm{dpc}$. (B) Box plots comparing the body weights of B6 embryos and cotransferred embryos (SJL/J or ICR). There were $21,31,20$, and 30 B6 embryos from B6 \& SJL/J cotransfer, SJL/J embryos from B6 \& SJL/J cotransfer, B6 embryos from B6 \& ICR cotransfer, and ICR embryos from B6 \& ICR cotransfer, respectively. $* * * * P<0.0001$. The scale bars in A represent $1 \mathrm{~cm}$. larger than B6 pups cotransferred with ICR embryos [at $\mathrm{P} 7,5.59 \pm 0.61(\mathrm{n}=21)$ vs. $4.73 \pm 0.46(\mathrm{n}=18)$; at $\mathrm{P} 21$, $14.13 \pm 1.14(\mathrm{n}=21)$ vs. $12.08 \pm 1.09(\mathrm{n}=18)$, mean \pm $\mathrm{SD}$. These results indicate that littermate strain can influence the postnatal growth of B6 mouse pups and that $\mathrm{SJL} / \mathrm{J}$ mice better promote growth than ICR mice.

\section{Experiment 3: No apparent effect of cotransferred strain on intrauterine growth of B6 embryos}

To examine whether the littermate strain also affects intrauterine growth of B6 mice, two groups of embryos were cotransferred (B6 \& SJL/J and B6 \& ICR) as in experiment 2. The recipients were sacrificed at $18.5 \mathrm{dpc}$, and the body weights of all embryos were measured (Fig. 2). The ICR embryos were the largest among the 4 groups at $18.5 \mathrm{dpc}(1.49 \pm 0.04 ; \mathrm{n}=30)$, while the body weights of the other three groups (B6 embryos in B6 \& $\mathrm{SJL} / \mathrm{J}$ cotransfer, SJL/J embryos in B6 \& SJL/J cotransfer, and B6 embryos in B6 \& ICR cotransfer) were not significantly different $[1.03 \pm 0.02(\mathrm{n}=21), 1.06 \pm 0.01$ $(\mathrm{n}=31)$, and $1.102 \pm 0.03(\mathrm{n}=20)$, respectively]. 


\section{Discussion}

In the present study, we compared the effects of cotransfer of B6 \& SJL/J embryos versus cotransfer of B6 $\&$ ICR embryos on pregnancy rate, number of pups/ embryos, intrauterine growth, and postnatal growth of B6 embryos/pups. We demonstrated that B6 mice from the $\mathrm{B} 6 \& \mathrm{SJL} / \mathrm{J}$ cotransfer displayed better postnatal growth than B6 mice from the B6 \& ICR cotransfer. Our results also show that cotransfer with 2-cell SJL/J embryos did not adversely affect pregnancy rate, number of pups/embryos, or intrauterine growth. Because B6 (including $\mathrm{C} 57 \mathrm{BL} / 6 \mathrm{~J}$ and $\mathrm{C} 57 \mathrm{BL} / 6 \mathrm{~N}$ ) is one of the most commonly used strains for the generation and maintenance of genetically modified mice [2], SJL/J embryos may be useful as a carrier in cotransfer when transferring a limited number of B6-derived genetically modified 2-cell mouse embryos.

Cotransfer of carrier embryos can assist the implantation and subsequent development of the embryos of interest. In this study, we transferred 2-cell B6 embryos along with 2-cell SJL/J or ICR embryos into pseudopregnant ICR recipients. Both 2-cell SJL/J embryos and 2-cell ICR embryos showed similar effects on the pregnancy rate as well as the number and percentage of B6 pups. This suggests that $\mathrm{SJL} / \mathrm{J}$ embryos can assist in the implantation and subsequent development of B6 embryo as well as ICR embryos. Previous studies have demonstrated the usefulness of performing cotransfer. For recovering cloned mouse embryos derived from somatic cell nuclear transfer, cotransfer of 2-cell ICR embryos effectively promotes implantation and subsequent embryonic development $[15,16]$. Similar positive effects of cotransfer have been reported for cloned embryos from the pig, rat, and rabbit $[13,14,20]$. These effects might be attributable to the fact that, in multiparous animals, a minimum number of healthy embryos is required to trigger and maintain pregnancy. Unknown damages caused by somatic cell nuclear transfer can reduce the number of healthy embryos [18], while cotransfer compensates for this by increasing the total number of healthy embryos to trigger and maintain pregnancy. Likewise, in the case of cryopreservation, some reports have described damage to freeze-thawed embryos [1,24], implying that cotransfer of carrier embryos could assist the implantation and subsequent development of freeze-thawed embryos.

Our study showed that the survival rate of 2-cell SJL/J embryos after freeze-thawing was comparable to those of 2-cell B6 and ICR embryos (Table 1). However, Byers et al. reported a very low survival rate after thawing of frozen 2-cell SJL/J embryos (values not reported) [3]. Although the reason for this discrepancy remains unclear, the difference in freeze-thawing methods may influence survival rate after freeze-thawing [vitrification (our study) versus slow freezing (study by Byers et al.)]. Furthermore, it would be interesting to compare SJL/J embryos derived from these two freezing methods as carrier embryos in cotransfer.

In this study, a larger number of 2-cell embryos (6-7 B6 embryos and 6-7 SJL/J or ICR embryos per oviduct; total of 27-28 embryos per female) was transferred. Therefore, it was difficult to evaluate the ability of the cotransferred SJL/J or ICR embryos to maintain pregnancy due to the existence of an excessive number of embryos transferred to recipient. We are not able to exclude the possibility of contributions of not only cotransferred SJL/J or ICR embryos but also B6 embryos to maintenance of pregnancy. Further analysis is required to determine the suitable number of $\mathrm{SJL} / \mathrm{J}$ embryos for maintenance of the state of pregnancy.

ICR females were used as the recipients of embryo transfer in this study and other studies $[11,16,22]$. Furthermore, CByB6F1/J, NMRI, C3H/HeN, and DBA/2J mice can also be used as recipients of embryo transfer $[3,21]$. It has been suggested that the maternal immune response to the fetus affects in vivo development of transferred mouse embryos [10]. When 2-cell embryos of the $\mathrm{MSM} / \mathrm{Ms}$ mouse strain, an inbred mouse strains derived from Japanese wild mice belonging to the same subspecies of Mus musculus (M. musculus molossinus), were transferred to an ICR female, no MSM/Ms pups were born alive because of the intrauterine death of fetuses during late gestation. Hasegawa et al. successfully rescued this incidence of fetal death with the combination of cyclosporine A and cotransfer of ICR embryos [10]. B6 \& SJL/J cotransfer, B6 transfer, and SJL/J transfer to ICR recipients, however, resulted in live pups without the use of cyclosporine A in this study. This implies that transfer of 2-cell $\mathrm{B} 6$ or $\mathrm{SJL} / \mathrm{J}$ embryos might modulate the maternal immune response to the fetus in a manner similar to 2-cell ICR embryos.

Our study clearly demonstrates a strong advantage of cotransfer with $\mathrm{SJL} / \mathrm{J}$ embryos used as a carrier especially with regard to postnatal growth. B6 infants from B6 \& SJL/J cotransfer are heavier than B6 infants from 
B6 \& ICR cotransfer. Surprisingly, at $18.5 \mathrm{dpc}, \mathrm{B} 6 \mathrm{em}-$ bryos from B6 \& SJL/J cotransfer were not significantly different from B6 embryos from B6 \& ICR cotransfer. The increased body weight of B6 infants from B6 \& $\mathrm{SJL} / \mathrm{J}$ cotransfer was observed at all postnatal days examined, suggesting competition among littermates even at the neonatal stage. This result suggests that cohabitation with cotransfer-derived ICR pups has a minor but significant growth retardation effect on B6-background pups. Therefore, when performing a cotransfer of B6 and ICR embryos, we recommend early sacrifice of the ICR pups to achieve better growth of the B6 pups. Furthermore, the comparison of the B6 \& SJL/J cotransfer with the B6 \& ICR cotransfer in this study revealed a novel experimental model system for examination of competition among littermates during the prenatal and infant periods [5].

$\mathrm{SJL} / \mathrm{J}$, an inbred albino strain of mice derived in 1963, has been proposed as an animal model for human Hodgkin's disease due to histological similarity to human lymphoma [8]. Furthermore, increasing immune dysfunction at both the cellular and humoral levels has been reported in SJL/J mice with age [19]. More recently, the performance of SJL/J mice following assisted reproductive technologies was reported [3]. Although Byers et al. reported lower fertilization rates for $\mathrm{SJL} / \mathrm{J}$ mice in IVF $(27.4 \pm 3.1 \%)$ [3], our IVF rate for SJL/J mice was comparable to those of B6 and ICR mice (Table 1). Because our IVF protocol, which did not have reduced glutathione in the fertilization medium, also showed a low IVF rate $(17.2 \pm 14.9 \%, n=3$, unpublished data), an IVF protocol using reduced glutathione would be useful for producing 2-cell SJL/J embryos and live SJL/J mice via IVF. Taken together, our study broadens the utilization of SJL/J mice, not only as an immunological disease model but also as carrier embryos for cotransfer in assisted reproductive technology.

In summary, we demonstrated that B6 infants from B6 \& SJL/J cotransfer weigh more than B6 infants from B6 \& ICR cotransfer. Cotransfer of either SJL/J or ICR embryos had similar effects on maintenance of pregnancy, number of pups born, and intrauterine growth. The cotransfer of SJL/J embryos will be useful, not only as carrier embryos with B6-background embryos but also as a model system to examine competition among littermates.

\section{Acknowledgments}

We are grateful to Drs. Toru Takeo and Naomi Nakagata and members of the Center for Animal Resources and Development, Kumamoto University for their kind instruction on embryo manipulation techniques. We acknowledge Ms. Junko Shuto for her excellent secretarial assistance and Ms. Ayako Morita and the staff of the Bioresource Center, Gunma University for their help. This work was supported by Grants-in-Aid for Young Scientists (B) (JSPS) (No. 19770147, 22700326), a Grant-in-Aid for Scientific Research (C) (JSPS) (No. 24500375), and the Takeda Science Foundation (to R.K.).

\section{References}

1. Bagis, H., Akkoc, T., Taskin, C., and Arat, S. 2010. Comparison of different cryopreservation techniques: higher survival and implantation rate of frozen-thawed mouse pronuclear embryos in the presence of beta-mercaptoethanol in postthaw culture. Reprod. Domest. Anim. 45: e332-e337. [Medline] [CrossRef]

2. Brown, S.D. and Moore, M.W. 2012. The International Mouse Phenotyping Consortium: past and future perspectives on mouse phenotyping. Mamm. Genome 23: 632-640. [Medline] [CrossRef]

3. Byers, S.L., Payson, S.J., and Taft, R.A. 2006. Performance of ten inbred mouse strains following assisted reproductive technologies (ARTs). Theriogenology 65: 1716-1726. [Medline] [CrossRef]

4. Canseco, R.S., Sparks, A.E., Page, R.L., Russell, C.G., Johnson, J.L., Velander, W.H., Pearson, R.E., Drohan, W.N., and Gwazdauskas, F.C. 1994. Gene transfer efficiency during gestation and the influence of co-transfer of non-manipulated embryos on production of transgenic mice. Transgenic Res. 3: 20-25. [Medline] [CrossRef]

5. Crozier, W.J. and Enzmann, E.V. 1935. On the Relation between Litter Size, Birth Weight, and Rate of Growth, in Mice. J. Gen. Physiol. 19: 249-263. [Medline] [CrossRef]

6. Davisson, M. 2006. FIMRe: Federation of International Mouse Resources: global networking of resource centers. Mamm. Genome 17: 363-364. [Medline] [CrossRef]

7. Donahue, L.R., Hrabe de Angelis, M., Hagn, M., Franklin, C., Lloyd, K.C., Magnuson, T., McKerlie, C., Nakagata, N., Obata, Y., Read, S., Wurst, W., Hörlein, A., and Davisson, M.T. 2012. Centralized mouse repositories. Mamm. Genome 23: 559-571. [Medline] [CrossRef]

8. Dunn, T.B. 1968. Neoplastic properties of animal cell lines-summary. Natl. Cancer Inst. Monogr. 29: 555-557. [Medline]

9. Guan, M., Marschall, S., Raspa, M., Pickard, A.R., and Fray, M.D. 2012. Overview of new developments in and the future of cryopreservation in the laboratory mouse. Mamm. Genome 23: 572-579. [Medline] [CrossRef] 
10. Hasegawa, A., Mochida, K., Matoba, S., Yonezawa, K., Ohta, A., Watanabe, G., Taya, K., and Ogura, A. 2012. Efficient production of offspring from Japanese wild-derived strains of mice (Mus musculus molossinus) by improved assisted reproductive technologies. Biol. Reprod. 86: 167, 1-7. [Medline] [CrossRef]

11. Kaneda, H., Taguma, K., Suzuki, C., Ozaki, A., Nakamura, C., Hachisu, A., Kobayashi, K., Wakana, S., and Shiroishi, T. 2007. An optimal embryo transfer condition for the effective production of DBA/2J mice. Exp. Anim. 56: 385-388. [Medline] [CrossRef]

12. Kawano, K., Yamamura, A., Ogawa, M., Kouyama, T., Nishikawa, T., Nakashima, T., Shimoda, T., Mikoda, N., and Nakagata, N. 2001. Transfer of mouse embryos $\sim$ Combinations of embryos obtained from transgenic and ICR mouse strain . Exp. Anim. 50: 212.

13. King, T.J., Dobrinsky, J.R., Zhu, J., Finlayson, H.A., Bosma, W., Harkness, L., Ritchie, W.A., Travers, A., McCorquodale, C., Day, B.N., Dinnyés, A., De Sousa, P.A., and Wilmut, I. 2002. Embryo development and establishment of pregnancy after embryo transfer in pigs: coping with limitations in the availability of viable embryos. Reproduction 123: 507-515. [Medline] [CrossRef]

14. Meng, Q., Polgar, Z., Liu, J., and Dinnyes, A. 2009. Live birth of somatic cell-cloned rabbits following trichostatin A treatment and cotransfer of parthenogenetic embryos. Cloning Stem Cells 11: 203-208. [Medline] [CrossRef]

15. Meng, Q., Wang, M., Stanca, C.A., Bodo, S., and Dinnyes, A. 2008. Cotransfer of parthenogenetic embryos improves the pregnancy and implantation of nuclear transfer embryos in mouse. Cloning Stem Cells 10: 429-434. [Medline] [CrossRef]

16. Mizutani, E., Yamagata, K., Ono, T., Akagi, S., Geshi, M., and Wakayama, T. 2012. Abnormal chromosome segregation at early cleavage is a major cause of the full-term developmental failure of mouse clones. Dev. Biol. 364: 56-65. [Med- line] [CrossRef]

17. Nakao, K., Nakagata, N., and Katsuki, M. 1997. Simple and efficient vitrification procedure for cryopreservation of mouse embryos. Exp. Anim. 46: 231-234. [Medline] [CrossRef]

18. Ogura, A., Inoue, K., and Wakayama, T. 2013. Recent advancements in cloning by somatic cell nuclear transfer. Philos. Trans. R. Soc. Lond. B Biol. Sci. 368: 20110329. [Medline] [CrossRef]

19. Owens, M.H. and Bonavida, B. 1976. Immune functions characteristic of SJL/J mice and their association with age and spontaneous reticulum cell sarcoma. Cancer Res. 36: 1077-1083. [Medline]

20. Popova, E., Bader, M., and Krivokharchenko, A. 2006. Fullterm development of rat after transfer of nuclei from twocell stage embryos. Biol. Reprod. 75: 524-530. [Medline] [CrossRef]

21. Rose, C., Schwegler, H., Hanke, J., and Yilmazer-Hanke, D.M. 2012. Pregnancy rates, prenatal and postnatal survival of offspring, and litter sizes after reciprocal embryo transfer in DBA/2JHd, C3H/HeNCrl and NMRI mice. Theriogenology 77: 1883-1893. [Medline] [CrossRef]

22. Takeo, T. and Nakagata, N. 2010. Combination medium of cryoprotective agents containing L-glutamine and methylbeta-cyclodextrin in a preincubation medium yields a high fertilization rate for cryopreserved C57BL/6J mouse sperm. Lab. Anim. 44: 132-137. [Medline] [CrossRef]

23. Takeo, T. and Nakagata, N. 2011. Reduced glutathione enhances fertility of frozen/thawed C57BL/6 mouse sperm after exposure to methyl-beta-cyclodextrin. Biol. Reprod. 85: 1066-1072. [Medline] [CrossRef]

24. Uechi, H., Tsutsumi, O., Morita, Y., Takai, Y., and Taketani, Y. 1999. Comparison of the effects of controlled-rate cryopreservation and vitrification on 2-cell mouse embryos and their subsequent development. Hum. Reprod. 14: $2827-$ 2832. [Medline] [CrossRef] 